\title{
Determination of Regional Intestinal Permeability of Diclofenac and Metoprolol Using a Newly-Developed and Validated High Performance Liquid Chromatographic Method
}

\author{
Mustafa Sinan Kaynak ${ }^{1,2}$, Ebru Buyuktuncel ${ }^{3}$, Hatice Caglar $^{3}$ and Selma Sahin ${ }^{1}$ \\ ${ }^{1}$ Hacettepe University, Faculty of Pharmacy, Department of Pharmaceutical Technology, 06100, Ankara, ${ }^{2}$ Inönü University, \\ Faculty of Pharmacy, Department of Pharmaceutical Technology, ${ }^{3}$ Inönü University, Faculty of Pharmacy, Department of \\ Analytical Chemistry, 44280, Malatya, Turkey
}

*For correspondence: Email: sahin.selma@gmail.com; Tel: +90 312310 1524; Fax: +90 3123100906

\begin{abstract}
Purpose: To develop a simple and rapid reversed-phase high performance liquid chromatographic (HPLC) method with UV detection for the simultaneous determination of diclofenac, metoprolol tartrate, phenol red and propyl paraben in intestinal segments.

Methods: The mobile phase consisted of $55 \%$ methanol, $45 \%$ of $12.5 \mathrm{mM}$ potassium dihydrogen phosphate $\left(\mathrm{KH}_{2} \mathrm{PO}_{4}\right)$ aqueous solution, adjusted to $\mathrm{pH} 7.0$ using $0.2 \mathrm{~N}$ sodium hydroxide $(\mathrm{NaOH})$ solution, and to which $0.3 \%(\mathrm{~V} / \mathrm{V})$ triethylamine was added. Analysis was run at a flow rate of 1.0 $\mathrm{mL} / \mathrm{min}$ with a $12 \mathrm{~min}$ total run time at ambient temperature. The developed method was successfully applied to determination of the analytes in samples obtained from in situ single pass intestinal perfusion (SPIP) studies.

Results: The calibration curves were linear for all compounds $(r>0.999)$ with a limit of detection $(L O D)$ of $0.005,0.1,0.075 \mu \mathrm{g} / \mathrm{mL}$, and limit of quantification of $0.1,0.3,0.2 \mu \mathrm{g} / \mathrm{mL}$ for metoprolol tartrate, phenol red and diclofenac respectively. The coefficient of variation for intra-day and inter-day precision was $<5 \%$ and accuracy was between 98 and $102 \%$. Based on SPIP and HPLC studies, the estimated mean permeability in jejunum, ileum and colon was $0.319 \pm 0.184,0.639 \pm 0.241$ and $0.843 \pm 0.517 x$ $10^{-4} \mathrm{~cm} / \mathrm{sec}$, respectively, for metoprolol tartrate while the corresponding permeability values were 1.585 $\pm 0.729,1.154 \pm 0.433$ and $1.775 \pm 1.576 \times 10^{-4} \mathrm{~cm} / \mathrm{sec}$ for diclofenac.

Conclusion: The findings indicate that diclofenac is a highly permeable compound and its absorption occurs throughout the intestinal tract. Furthermore, the developed method is suitable for the analysis of diclofenac and metoprolol in intestinal regions.
\end{abstract}

Keywords: Biopharmaceutics classification system, Diclofenac, Metoprolol tartrate, Segmental permeability, Intestinal absorption, Validation

Tropical Journal of Pharmaceutical Research is indexed by Science Citation Index (SciSearch), Scopus, International Pharmaceutical Abstract, Chemical Abstracts, Embase, Index Copernicus, EBSCO, African Index Medicus, JournalSeek, Journal Citation Reports/Science Edition, Directory of Open Access Journals (DOAJ), African Journal Online, Bioline International, Open-J-Gate and Pharmacy Abstracts

\section{INTRODUCTION}

Absorption of orally administered drugs could vary at different segment of the small intestine such as duodenum, jejunum, and ileum [1,2]. The knowledge of the site of absorption of a drug and absorption characteristics in the intestine is especially important for the development of modified release formulations [3]. Since the small intestinal transit of drug formulations is about 3 $4 \mathrm{~h}$, significant part of the dose of drug in a modified release product can possibly reach the 
colon. This means that the absorption of the drug which is used for modified release formulations has to be classified as high permeability in the entire intestine. It is important to understand the absorption characteristics in the entire intestinal tract for BCS class II and III drugs, in order to identify and develop strategies for modifiedrelease formulations [4].

Diclofenac is a non-steroidal anti-inflammatory drug with analgesic, anti-inflammatory and antipyretic properties, was chosen as the model compound [5]. It is reported that absorption of diclofenac occurs throughout the intestinal tract [6]. Various oral solid dosage forms (e.g. immediate release, enteric coated and sustained release) have been developed and still available in the market due to diclofenac's side effects in the stomach. For enteric coated diclofenac sodium tablets, drug is released once the tablet reaches the duodenum, with subsequent rapid absorption [7].

Several HPLC methods have been described in the literature for the determination of diclofenac in raw material, pharmaceutical dosage forms, and biological fluids $[7,8]$. Also HPLC methods are available in literature for separate determination of metoprolol tartrate or phenol red [2,8-11]. Therefore, the aim of this study was to determine segmental permeability and absorption characteristics of diclofenac using a newly developed and validated reversed-phase liquid chromatographic method for the simultaneous determination of diclofenac, metoprolol tartrate and phenol red in intestinal perfusion samples. In these studies, metoprolol tartarate was used as a reference standard to compare the permeability coefficient of diclofenac. Phenol red was used as a zero permeability marker for correction of permeability coefficient for water transport [2].

\section{EXPERIMENTAL}

\section{Chemicals and reagents}

Metoprolol tartrate was a gift by Novartis Drug Co., Turkey and diclofenac sodium salt by Deva Drug Co., Turkey. Phenol red was purchased from Merck, Germany and propyl paraben from Sigma Chemical Company (USA). Potassium phosphate monobasic was supplied from Riedelde Haën (Germany). Water was purified (18 $\mathrm{M} \Omega / \mathrm{cm}$ ) from water purification system (New Human Power I, Korea). Methanol was of HPLC grade, and all other reagents were of analytical grade.
Instrumentation and chromatographic conditions

The integrated high performance liquid chromatography system (LC 1100, HewlettPackard, USA) equipped with a diode-array detector, a quaternary pump, a degasser, a Rheodyne injection valve equipped with $20 \mu \mathrm{L}$ loop and a column oven. The separation was carried out using an ACE 5 C18 column (150 x $4.6 \mathrm{~mm}, 5 \mu \mathrm{m}$ ) with a guard cartridge of the same material at room temperature. Minipuls ${ }^{\circledR} 3$ (Gilson, USA) peristaltic pump was used for delivery of perfusion medium to the excised intestinal segments.

Isocratic chromatographic separation was applied. The mobile phase was a mixture of $55 \%$

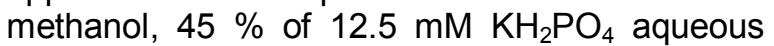
solution adjusted to $\mathrm{pH} 7.0$ using $0.2 \mathrm{~N} \mathrm{NaOH}$ solution, to which $0.3 \%(\mathrm{v} / \mathrm{v})$ triethylamine was added. Before use, the mobile phase was vacuum filtered through a $0.45 \mu \mathrm{m}$ nylon filter and degassed on-line by micro vacuum degasser which is equipped with the HPLC system. The chromatograms were monitored by UV detection at the wavelength of $205 \mathrm{~nm}$. Analysis was run at a flow rate of $1 \mathrm{~mL} / \mathrm{min}$ with a $12 \mathrm{~min}$ total run time at ambient temperature. The injection volume was $20 \mu \mathrm{L}$.

\section{Preparation of perfusion medium}

The perfusion medium consisted of $25 \mathrm{mM} \mathrm{NaCl}$, $10 \mathrm{mM} \mathrm{KCl}, 40 \mathrm{mM} \mathrm{Na}_{2} \mathrm{SO}_{4}, 20 \mathrm{mM} \mathrm{NaHCO}$ and $80 \mathrm{mM}$ mannitol. The $\mathrm{pH}$ of buffer was adjusted to 7.4 by ortho-phosphoric acid. Perfusion medium was freshly prepared and then filtered through $0.45 \mu \mathrm{m}$ membrane filter.

\section{Preparation of standard solutions}

Primary stock solutions for each compound in separate flasks were prepared by dissolving metoprolol tartrate, diclofenac sodium, propyl paraben and phenol red in methanol to produce concentration of $1 \mathrm{mg} / \mathrm{mL}$. Six standard solutions of different concentrations $(2.5,5,10,20,40,80$ $\mu \mathrm{g} / \mathrm{mL}$ for metoprolol tartrate and phenol red; 1.5 , $2.5,5,10,20,40 \mu \mathrm{g} / \mathrm{mL}$ for diclofenac) were prepared separately by spiking in blank perfusion solution. Finally, propyl paraben $(20 \mu \mathrm{g} / \mathrm{mL})$ was spiked into each standard calibration solution as the internal standard (IS).

\section{HPLC method validation procedure}

A full validation of assay consisting of selectivity, linearity, lower limit of detection (LOD) and limit of quantitation (LOQ), intra-day precision 
(repeatability), inter-day precision (intermediate precision), intra-day and inter-day accuracy of the method was performed according to the $\mathrm{ICH}$ description [12].

\section{Linearity}

Quantifications of metoprolol tartrate, phenol red and diclofenac were based on the calibration curves constructed under optimum conditions as the ratio of the peak areas of analyzed substance to internal standard $(y)$ against the concentration $(\mathrm{x})$.

\section{Precision and accuracy}

Three different concentrations of standard solutions were analyzed over five consecutive days and five times within the same day. Precision was expressed as the relative standard deviation (RSD) of the control sample concentrations, and accuracy was expressed as percentage recovery. Recoveries were calculated as peak area ratio of reference standard/analyte (spiked blank perfusion solution) at different concentration.

\section{Single-pass intestinal perfusion studies}

(SPIP)

All animal experiments were conducted using protocols approved by the İnönü University, Committee of Use and Care of Animals (Protocol no. 2010/11). Female Sprague Dawley rats (250 - $300 \mathrm{~g}$ ) were used for intestinal perfusion studies. Prior to each experiment, the rats were fasted overnight for about 12-18 $\mathrm{h}$ with free access to tap water.

The experimental procedure for the in situ single pass intestinal perfusion was performed according to the previously published reports [3]. The rats were anaesthetized using an intraperitoneal injection of pentobarbital (60 $\mathrm{mg} / \mathrm{kg}$ ). The abdomen was opened by a midline incision (3-4 cm). Jejunal $(10 \mathrm{~cm})$, ileal $(7 \mathrm{~cm})$ and colonal $(3 \mathrm{~cm})$ segments were carefully exposed and cannulated with flexible PVC tubing (inlet tubing, internal diameter (i.d.) $0.76 \mathrm{~mm}$; outlet tubing, id $1.70 \mathrm{~mm}$ ), and the tubings were then attached to the perfusion assembly which consisted of a perfusion pump (Minipuls ${ }^{\circledR} 3$, USA). In order to maintain an intact blood supply to the segments, care was taken and exposed segments were kept moist with $37^{\circ} \mathrm{C}$ saline solution. Perfusion medium incubated in a water bath at $37{ }^{\circ} \mathrm{C}$. Surgical area was then covered with parafilm to reduce evaporation.
In order to clean out any residual debris, the isolated segments were rinsed with blank perfusion medium at a flow rate of $0.5 \mathrm{~mL} / \mathrm{min}$ for $10 \mathrm{~min}$. At the beginning of the study, perfusion solution containing the model drug (diclofenac sodium) and the reference compounds (metoprolol tartrate and phenol red) was perfused through the exposed segments at a flow rate of $0.2 \mathrm{~mL} / \mathrm{min}$ for $60 \mathrm{~min}$. The concentrations were selected based on the oral dose of the drug products (diclofenac: 0.4 $\mathrm{mg} / \mathrm{mL}$; metoprolol tartrate: $0.8 \mathrm{mg} / \mathrm{mL}$; phenol red: $0.25 \mathrm{mg} / \mathrm{mL}$ ). Outlet samples were collected every $10 \mathrm{~min}$ in eppendorf tubes. At the end of each experiment, the animal was euthanatized with cervical dislocation and then the length of perfused segments was re-measured.

\section{Data analysis}

For calculation of effective permeability values $\left(P_{\text {eff }}\right)$, the measured $C_{\text {out }} / C_{\text {in }}$ ratio was corrected for water transport using equation 1 [13].

$$
\mathrm{C}_{\text {out }} / \mathrm{C}_{\text {in }}^{\prime}=\left[\left(\mathrm{C}_{\text {out }} / \mathrm{C}_{\text {in }}\right) \times\left(\mathrm{C}_{\text {inphenolred }} / \mathrm{C}_{\text {outphenolred }}\right)\right]
$$

where $\mathrm{C}_{\text {inphenolred }}$ is the inlet phenol red concentration, and $\mathrm{C}_{\text {outphenolred }}$ is the outlet phenol red concentration.

The effective permeability $\left(P_{\text {eff }}\right)$ values of the drug across the rat gut wall were calculated assuming the "plug flow" model given in the following equation [14].

$P_{\text {eff }}(\mathrm{cm} / \mathrm{sec})=\left[-\mathrm{Q} \ln \left(C_{\text {out }} / C_{\text {in }}^{\prime}\right)\right] / 2 \pi R L$

where $Q$ is the flow rate of perfusion solution (mL/sec); $\mathrm{C}_{\text {out }}^{\prime} / \mathrm{C}^{\prime}$ in is the corrected concentration ratio of outlet to inlet concentration (Equation 1). $R$ is the radius of the perfused intestinal segment (for jejunum and ileum $\mathrm{R}=0.2 \mathrm{~cm}$, for colon $\mathrm{R}=$ $0.25) ; L$ is the length of the intestinal segment (cm) $[3,15,16]$.

Net water flux (NWF) values were estimated based on inlet $\left(\mathrm{C}_{\text {in }}\right)$ and outlet $\left(\mathrm{C}_{\text {out }}\right)$ concentrations of phenol red using the following equation:

NWF $=\left[1-\left(C_{\text {outphenolred }} / C_{\text {inphenolred }}\right) / L\right] \times Q_{\text {in }} \ldots(3)$

A negative net water flux indicates loss of fluid from the mucosal side (lumen) to the serosal side (blood). A positive net water flux indicates secretion of fluid into the segment [14]. 


\section{Statistical analysis}

All tabulated results are shown as mean \pm standard deviation (SD). In order to determine differences among the experimental groups, the non-parametric Kruskal - Wallis test was used for multiple comparisons, and while two-tailed nonparametric Mann - Whitney U test for two - group comparisons when appropriate. $p<0.05$ was considered statistically significant.

\section{RESULTS}

In our study, investigations were performed in order to determine the permeability characteristics of diclofenac sodium in the gastrointestinal tract. Prior to permeability studies, in order to save time and reduce solvent consumption, a simple, sensitive and unique HPLC method was developed and validated for the simultaneous determination of diclofenac sodium, metoprolol tartarate and phenol red from SPIP studies samples.

\section{Validation}

The retention time of diclofenac decreased with decreasing $\mathrm{KH}_{2} \mathrm{PO}_{4}$ concentration, hence the concentration of $\mathrm{KH}_{2} \mathrm{PO}_{4}$ in the mobile phase was fixed at $0.0125 \mathrm{M}$ (Figure 1). When the effect of mobile phase $\mathrm{pH}$ on the separation of model and reference compounds was investigated, it was found that the retention time of diclofenac increased with decreasing $\mathrm{pH}$ of the mobile phase (Figure 2). Therefore, the optimum composition of the mobile phase was chosen as

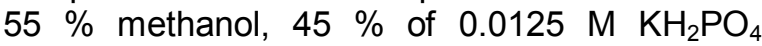
adjusted to $\mathrm{pH} 7.0$ with $0.3 \%(\mathrm{v} / \mathrm{v})$ triethylamine. The retention times for metoprolol tartrate, phenol red, propyl paraben (IS) and diclofenac using optimum conditions were 2.3, 2.7, 8.4 and 11.4 min, respectively.

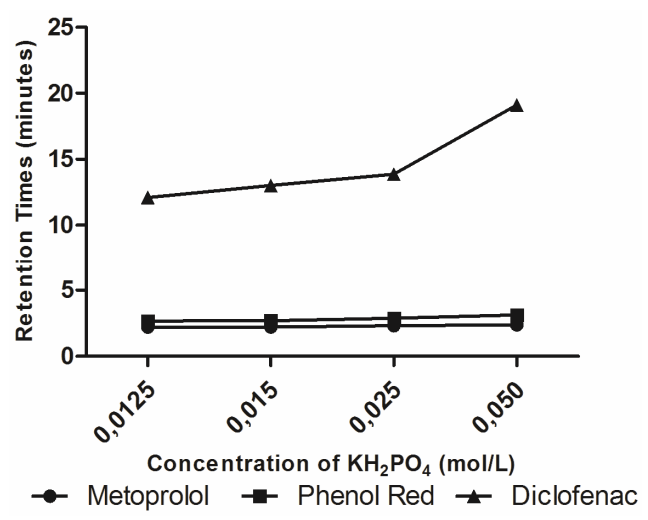

Figure 1: Effect of $\mathrm{KH}_{2} \mathrm{PO}_{4}$ concentration in the mobile phase on the retention times of metoprolol, phenol red and diclofenac

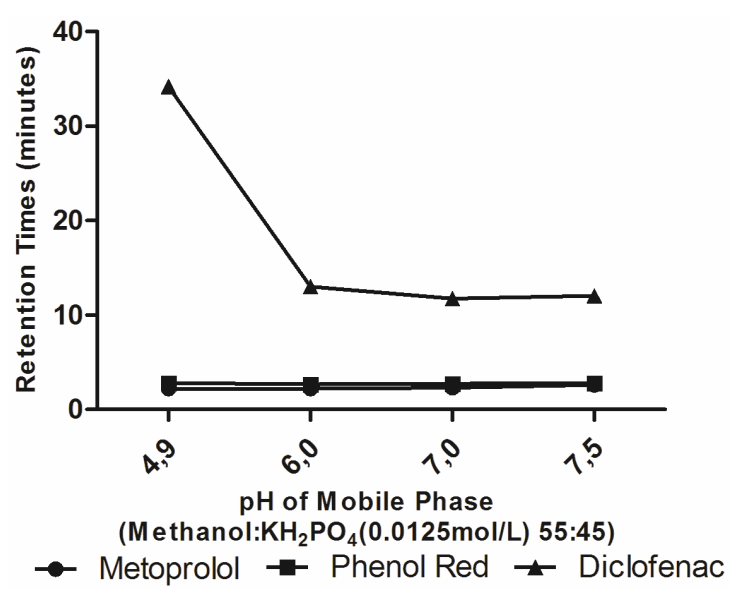

Figure 2: Effect of $\mathrm{pH}$ of the mobile phase on the retention times of metoprolol, phenol red and diclofenac

\section{Selectivity}

There was no interfering peak on the chromatogram following injection of blank perfusion solution into the HPLC column (Figure 3 ). The chromatogram obtained from standard solution was identical with that obtained from spiked solution containing equivalent concentration of metoprolol tartrate, phenol red, propyl paraben (IS) and diclofenac (Figure 3). Based on the results, the proposed method was considered to be selective.

\section{System suitability tests}

System suitability test parameters were checked to ensure that the system is working correctly during the analysis. The important parameter which is the time at which buffer peaks appear to, was $1.53 \mathrm{~min}$ in the analysis. Capacity factor $\left(k^{\prime}\right)$ values were $0.50,0.76$ and 6.44 for metoprolol tartrate, phenol red and diclofenac, respectively. Selectivity factor $(\alpha)$ was found to be 1.52 for separation of metoprolol tartrate and phenol red and 8.45 for the separation of phenol red and diclofenac. The resolution value for the separation of metoprolol tartrate and phenol red was 1.63. A value of 1.50 for resolution implies a complete separation of two compounds. For the column used in this study, the theoretical plate numbers were 1360, 1870 and 3253 metoprolol tartrate, phenol red and diclofenac, respectively. The height equivalent to theoretical plate was $0.11,0.08$ and $0.046 \mathrm{~mm}$, respectively. The calculated tailing factors of $1.03,1.08$ and 1.18 were obtained for metoprolol tartrate, phenol red and diclofenac peaks, respectively which are in the acceptable range of $0.5 \leq \mathrm{T} \leq 2$. 

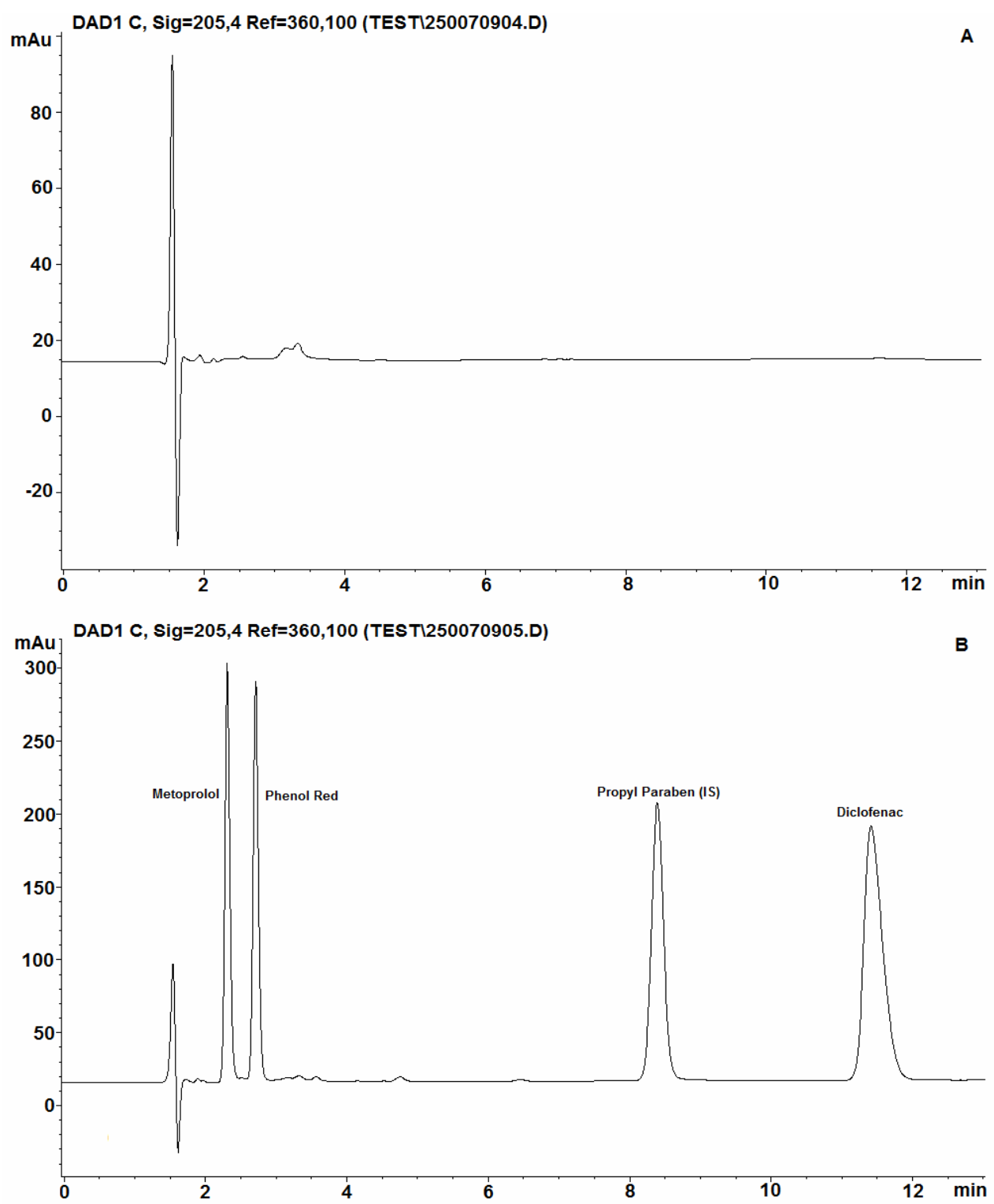

Figure 3: HPLC chromatograms of blank perfusion solution collected from outlet tubing (A) and standard solutions spiked in blank perfusion solution $(20 \mu \mathrm{g} / \mathrm{mL})(B)$. The retention times of metoprolol, phenol red, internal standard (propyl paraben) and diclofenac were 2.302, 2.703, 8.385 and $11.407 \mathrm{~min}$, respectively

\section{Linearity}

The calibration curves were found to be linear in the range of $0.1-80 \mu \mathrm{g} / \mathrm{mL}$ for metoprolol tartrate, $0.3-80 \mu \mathrm{g} / \mathrm{mL}$ for phenol red, and $0.2-40 \mu \mathrm{g} / \mathrm{mL}$ for diclofenac The peak shapes and symmetries were lost after injection of $40 \mu \mathrm{g} / \mathrm{mL}$ of diclofenac.

\section{Sensitivity}

The highest concentration that can be quantified (LOQ; signal-to-noise ratio $\mathrm{S} / \mathrm{N}>10$ ) with acceptable accuracy and precision was 0.100 , 0.300 and $0.200 \mu \mathrm{g} / \mathrm{mL}$ for metoprolol tartrate, phenol red and diclofenac, respectively. Furthermore, the limits of detection (LOD; signalto-noise ratio $\mathrm{S} / \mathrm{N}>3$ ) were $0.050,0.100$ and $0.075 \mu \mathrm{g} / \mathrm{mL}$ for metoprolol tartrate, phenol red and diclofenac, respectively when $20 \mu \mathrm{L}$ volume of sample was injected (Table 1).

\section{Precision and accuracy}

The intra-assay (intra-day) and between-assay (inter-day) precision and accuracy results for metoprolol tartrate, phenol red, diclofenac and propyl paraben in blank perfusion solution at low, medium and high concentrations are summarized in Table 2. 


\section{Permeability}

NWF values of intestinal segments were $0.057 \pm$ $0.041,0.067 \pm 0.073,0.288 \pm 0.351 \mu \mathrm{L} / \mathrm{sec} / \mathrm{cm}$ for jejunum, ileum and colon, respectively, indicating water secretion to lumen. Metoprolol tartrate served as a marker for the integrity of the experiment, and as a reference standard for the permeability class boundary, and phenol red as a non-absorbable marker. The permeability $\left(P_{\text {eff }}\right)$ values calculated for metoprolol tartrate and diclofenac following simultaneous perfusion of jejunum, ileum and colon are depicted in Figure 4 , and results were summarized in Table 3.

The permeability values estimated for metoprolol tartrate increased in the order of colon > ileum > jejunum while for estimated intestinal permeability values were in the order of colon > ileum (Figure 4 and Table 3). Depending on our $P_{\text {eff }}$ values of diclofenac and metoprolol, diclofenac had higher permeability than metoprolol in all intestinal segments.

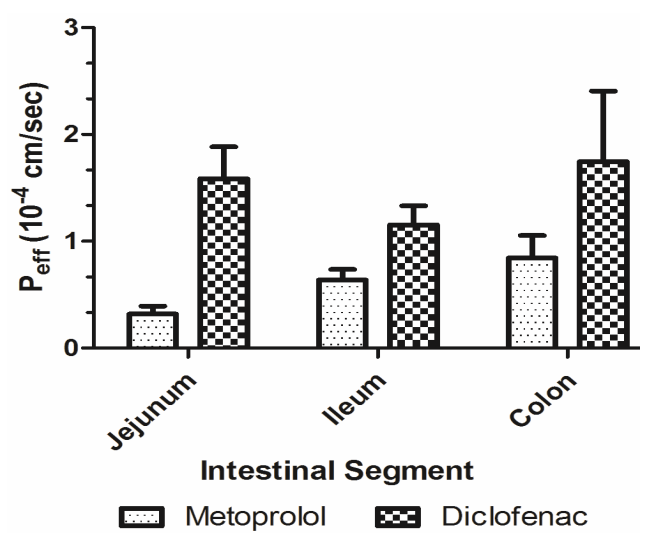

Figure 4: The permeability coefficients $\left(P_{\text {eff; }} \mathrm{cm} / \mathrm{sec}\right)$ of metoprolol tartrate and diclofenac obtained from the simultaneous perfusion of jejunum, ileum and colon of the rat (mean $\pm S D, n=6)$

Table 1: The linearity of the developed method $(n=6)$

\begin{tabular}{llll}
\hline Validation parameter & Metoprolol & Phenol Red & Diclofenac \\
\hline Regression equation & $\mathrm{y}=0.0371 \mathrm{x}+0.0064$ & $\mathrm{y}=0.0329+0.0034$ & $\mathrm{Y}=0.0811 \mathrm{x}+0.0035$ \\
Standard error of intercept & 0.0003 & 0.0002 & 0.0005 \\
Standard error of slope & 0.0004 & 0.0005 & 0.0006 \\
Correlation coefficient $(\mathrm{r})$ & 0.9999 & 0.9995 & 0.9997 \\
Linearity range $(\mu \mathrm{g} / \mathrm{mL})$ & $0.1-80$ & $0.3-80$ & $0.2-40$ \\
LOD $(\mu \mathrm{g} / \mathrm{mL})$ & 0.050 & 0.100 & 0.075 \\
LOQ $(\mu \mathrm{g} / \mathrm{mL})$ & 0.100 & 0.300 & 0.200 \\
\hline
\end{tabular}

Table 2: The intra-day and inter-day precision and accuracy results of the developed method $(n=6)$

\begin{tabular}{|c|c|c|c|c|c|}
\hline \multirow[b]{2}{*}{ Analyte } & \multirow{2}{*}{$\begin{array}{l}\text { Added Amount of } \\
\text { Compound }(\mu \mathrm{g} / \mathrm{mL})\end{array}$} & \multirow{2}{*}{$\begin{array}{l}\text { Intra-day } \\
\text { Precision } \\
\text { (RSD \%) }\end{array}$} & \multicolumn{3}{|c|}{ Inter-day } \\
\hline & & & $\begin{array}{l}\text { Accuracy } \\
(\%)\end{array}$ & $\begin{array}{l}\text { Precision } \\
\text { (RSD \%) }\end{array}$ & $\begin{array}{l}\text { Accuracy } \\
\text { (\%) }\end{array}$ \\
\hline \multirow[t]{3}{*}{ Metoprolol } & 2.50 & 4.31 & 100.77 & 4.47 & 101.23 \\
\hline & 10.00 & 1.29 & 99.61 & 1.60 & 99.43 \\
\hline & 40.00 & 3.40 & 98.75 & 3.75 & 98.58 \\
\hline \multirow[t]{3}{*}{ Phenol Red } & 2.50 & 4.49 & 98.32 & 4.74 & 97.93 \\
\hline & 10.00 & 3.76 & 99.60 & 3.95 & 99.43 \\
\hline & 40.00 & 2.31 & 98.52 & 2.55 & 98.69 \\
\hline \multirow[t]{3}{*}{ Diclofenac } & 2.50 & 3.98 & 104.84 & 3.82 & 102.87 \\
\hline & 10.00 & 2.32 & 101.34 & 3.54 & 103.35 \\
\hline & 40.00 & 1.95 & 101.60 & 4.16 & 102.11 \\
\hline \multirow{3}{*}{ Propyl paraben } & 2.50 & 3.93 & 100.14 & 3.43 & 98.54 \\
\hline & 20.00 & 3.24 & 100.58 & 2.97 & 99.12 \\
\hline & 40.00 & 1.34 & 99.66 & 2.64 & 102.20 \\
\hline
\end{tabular}

Table 3: Permeability coefficient values $\left(\mathrm{P}_{\text {eff; }} \mathrm{cm} / \mathrm{sec}\right)$ estimated for metoprolol tartrate and diclofenac following in situ single pass rat intestinal perfusion of different intestinal segments*

\begin{tabular}{|c|c|c|c|c|c|}
\hline \multirow{2}{*}{ Drug } & \multirow{2}{*}{$\begin{array}{l}\text { Highest } \\
\text { prescribed } \\
\text { dose }(\mathrm{mg})\end{array}$} & \multirow{2}{*}{$\begin{array}{l}\text { Concentration in } \\
\text { perfusate } \\
(\mathrm{mg} / \mathrm{mL})\end{array}$} & \multicolumn{3}{|c|}{$P_{\text {eff }}\left(.10^{-4} \mathrm{~cm} / \mathrm{sec}\right)$} \\
\hline & & & Jejunum & Ileum & Colon \\
\hline Metoprolol & 200 & 0.800 & $0.319 \pm 0.184^{1}$ & $0.639 \pm 0.241^{2}$ & $0.843 \pm 0.517^{3}$ \\
\hline Diclofenac & 100 & 0.400 & $1.585 \pm 0.729^{1}$ & $1.154 \pm 0.433^{2}$ & $1.775 \pm 1.576^{3}$ \\
\hline
\end{tabular}

${ }^{*}$ Metoprolol tartrate was co-perfused with diclofenac as a reference standard for permeability in close proximity to the low/high permeability class boundary; results are expressed as mean $\pm S D,(n=6) ;{ }^{1} p=0.006,{ }^{2} p=0.037,{ }^{3} p$ $=0.262$ 


\section{DISCUSSION}

According to the selectivity results, the proposed method was considered to be selective. For an optimum separation, capacity factor should be in the range of $0.5<k^{\prime}<10$. Our method's capacity factors were within acceptable limits. The resolution value for separation of metoprolol tartrate and phenol red implied a complete separation of two compounds. The calculated tailing factors obtained for metoprolol tartrate, phenol red and diclofenac peaks were in the acceptable range of $0.5 \leq \mathrm{T} \leq 2$. Collectively, all these results suggest the suitability of the system used for the analysis of the model and reference compounds. The calibration curves were linear for metoprolol tartrate, phenol red and diclofenac. Values of LOD and LOQ for model and test drugs obtained by the proposed method indicate that the method is sensitive. Based on the precision and accuracy results, the method was adjudged to be accurate and precise for intended purpose and minor variations did not affect the analysis.

The intestinal barrier function might be affected by un-physiological leakage across the intestinal segment. This could be one of the reasons for inconsistent permeability results obtained from the in situ and in vitro models $[2,3,17]$. Therefore, for the determination of the extent of water exchange across various intestinal segments, phenol red was added to the perfusion solution as a non-absorbable marker in the present study. Estimated NWF values indicate water secretion. These results indicate that stable intestinal barrier function was maintained for jejunum, ileum and colon.

The single-pass intestinal perfusion method was shown to be a precise method to predict in vivo oral absorption performance of drugs in humans $[13,14,18]$. Comparison of these segmental permeability values by means of Kruskal - Wallis and Mann - Whitney $U$ tests demonstrated that only the jejunal and colonic $P_{\text {eff }}$ values were significantly different $(p=0.016)$. Although there is no results available in the literature for colonic permeability of metoprolol tartrate, our jejunal and ileal permeability values were very similar to the literature values of $0.20-0.59 \times 10^{-4} \mathrm{~cm} / \mathrm{sec}$ $[2,13,19]$.

Very similar $P_{\text {eff }}$ values estimated for diclofenac in all segments can be used to support these observations. Our $\mathrm{P}_{\text {eff }}$ values estimated for diclofenac had positive correlation with the literature values reported for diclofenac (duodenum: $2.01 \pm 0.45 \times 10^{-4} \mathrm{~cm} / \mathrm{sec}$, jejunum: $1.16 \pm 0.32 \times 10^{-4} \mathrm{~cm} / \mathrm{sec}$ and ileum: $1.02 \pm 0.33$ $x \quad 10^{-4} \mathrm{~cm} / \mathrm{sec}$ [20]. According to Biopharmaceutics Classification System (BCS), drugs can be assigned as highly permeable if its $P_{\text {eff }}$ value is higher than, that of metoprolol tartrate's (reference standard for BCS permeability boundary) [19]. Our results clearly show that $P_{\text {eff }}$ values of diclofenac are significantly higher than metoprolol tartrate's in all segments, indicating that diclofenac is a highly permeable compound.

The oral absorption of a drug is influenced by both its aqueous solubility and intestinal permeability. Various methods are recommended for determination of intestinal permeability of a compound. These methods include in vivo studies in humans, e.g., mass balance studies, absolute bioavailability studies and in vivo intestinal perfusion studies, in vivo or in situ intestinal perfusion studies using suitable animal models, and in vitro studies (e.g., permeation studies using excised human or animal intestinal tissues, in vitro permeation studies across a monolayer of cultured epithelial cells). Since in vivo studies in human are difficult to perform, time-consuming and expensive, regional permeability prediction of compounds using SPIP studies is of considerable interest for especially modified release formulation development. For accurate and reliable estimation of the permeability coefficients in these studies, it is essential to use a validated HPLC method. Otherwise, under- or over-estimation of permeability values because of the analytical method used may lead to misclassification of the compound in BCS.

\section{CONCLUSION}

A new HPLC method has been developed and validated for the simultaneous determination of diclofenac, metoprolol tartrate, phenol red and propyl paraben (IS) for application in SPIP studies. The developed method has been successfully applied for the determination of these compounds in samples obtained from in situ single pass intestinal perfusion studies. Based on SPIP results, diclofenac is a highly permeable compound and its absorption occurs throughout the intestinal tract.

\section{ACKNOWLEDGEMENT}

The authors would like to thank Novartis (Novartis Drug Co, Turkey) for providing metoprolol tartarate, and Deva (Deva Drug Co, Turkey) for providing diclofenac sodium salt. 


\section{REFERENCES}

1. Amidon GL, Lennernas $H$, Shah VP, Crison JR. A Theoretical basis for a Biopharmaceutic Drug Classification - the correlation of in-vitro drug product dissolution and in-vivo bioavailability. Pharm Res 1995; 12: 413-420.

2. Zakeri-Milani $P$, Valizadeh $H$, Azarmi $Y$, Jalali $M B$, Tajerzadeh $H$. Simultaneous determination of metoprolol, propranolol and phenol red in samples from rat in situ intestinal perfusion studies DARU 2006; 14: 102-108.

3. Nagare N, Damre A, Singh KS, Mallurwar SR, lyer $S$, Naik A, Chintamaneni M. Determination of site of absorption of propranolol in rat gut using in situ single-pass intestinal perfusion. Indian J Pharm Sci 2010; 72: 625-U315.

4. Lennernas $H$, Abrahamsson $B$. The use of biopharmaceutic classification of drugs in drug discovery and development: current status and future extension. J Pharm Pharmacol 2005; 57: 273-285.

5. Chuasuwan B, Binjesoh V, Polli JE, Zhang H, Amidon GL, Junginger HE, Midha KK, Shah VP, Stavchansky $S$, Dressman JB et al. Biowaiver monographs for immediate release solid oral dosage forms: Diclofenac sodium and diclofenac potassium. J Pharm Sci 2009; 98: 1206-1219.

6. Terhaag B, Hoffmann A, Barkworth M, Vens-Cappell B. Bioavailability of a new effervescent tablet of diclofenac. Int J Clin Pharmacol Ther 2000; 38: 546551.

7. Willis JV, Kendall MJ, Flinn RM, Thornhill DP, Welling $P G$. The pharmacokinetics of diclofenac sodium following intravenous and oral administration. Eur $\mathrm{J}$ Clin Pharmacol 1979; 16: 405-410.

8. Kaphalia L, Kaphalia BS, Kumar S, Kanz MF, TreinenMoslen M. Efficient high performance liquid chromatograph/ultraviolet method for determination of diclofenac and 4'-hydroxydiclofenac in rat serum. $J$ Chromatogr B Analyt Technol Biomed Life Sci 2006; 830: 231-237.

9. Klimes J, Sochor J, Dolezal P, Korner J. HPLC evaluation of diclofenac in transdermal therapeutic preparations. Int J Pharm 2001; 217: 153-160.
10. Sane RT, Samant RS, Nayak VG. High-Performance Liquid-Chromatographic determination of diclofenac sodium from pharmaceutical preparation. Drug Dev Ind Pharm 1987; 13: 1307-1314.

11. Beaulieu N, Lovering EG, Lefrancois J, Ong $H$. Determination of diclofenac sodium and relatedcompounds in raw-materials and formulations. J Assoc Anal Chem 1990; 73: 698-701.

12. ICH. Expert Working Group. International Conference on Harmonization of Technical Requirements for Registration of Pharmaceuticals for Human Use. Validation of Analytical Procedures: Text and Methodology Q2R1 [cited 2014 Feb 20]. Available from: http://www.ich.org/products/guidelines/quality/ article/quality-guidelines.html.

13. Kim JS, Mitchell S, Kijek P, Tsume Y, Hilfinger J, Amidon $G L$. The suitability of an in situ perfusion model for permeability determinations: Utility for BCS class I biowaiver requests. Mol Pharm 2006; 3: 686-694.

14. Fagerholm $U$, Johansson $M$, Lennernas $H$. Comparison between permeability coefficients in rat and human jejunum. Pharm Res 1996; 13: 1336-1342.

15. Komiya I, Park JY, Kamani A, Ho NFH, Higuchi WI. Quantitative mechanistic studies in simultaneous fluid-flow and intestinal-absorption using steroids as model solutes. Int J Pharm 1980; 4: 249-262.

16. Dahan A, Amidon GL. Segmental dependent transport of low permeability compounds along the small intestine due to P-glycoprotein: the role of efflux transport in the oral absorption of BCS class III drugs. Mol Pharm 2009; 6: 19-28.

17. Patel JR, Barve KH. Intestinal permeability of lamivudine using single pass intestinal perfusion. Indian J Pharm Sci 2012; 74: 478-U433.

18. Lennernas $H$. Animal data: the contributions of the Ussing Chamber and perfusion systems to predicting human oral drug delivery in vivo. Adv Drug Deliv Rev 2007; 59: 1103-1120.

19. Incecayir $T$, Tsume $Y$, Amidon GL. Comparison of the permeability of metoprolol and labetalol in rat, mouse, and Caco-2 cells: use as a reference standard for BCS classification. Mol Pharm 2013; 10: 958-966.

20. Idkaidek NM, Jilani JA, Mansi IA. Evaluation of hydroxyethyldiclofenac intestinal absorption in rats Saudi Pharm J 2005; 13: 158-163. 